\title{
Os dispositivos móveis em contextos educativos: um estudo comparativo sobre as representações de utilização de telemóveis entre professores e alunos
}

\author{
Carrega, João \\ Diretor Jornal Ensino Magazine, Castelo Branco, Portugal \\ carrega@rvj.pt
}

Oria Segura, Maria Rosa

Universidade de Extremadura, Badajoz, Espanha

mros@unex.es

\begin{abstract}
Ruivo, João
Instituto Politécnico de Castelo Branco e Centro de Investigação de Políticas e Sistemas Educativos (CIPSE), do Instituto Politécnico de Leiria; Castelo Branco, Portugal ruivo@ipcb.pt
\end{abstract}

\section{Resumo}

O combate à iliteracia digital é um dos maiores desafios que hoje a escola enfrenta. De um lado estão alunos que cresceram com as novas tecnologias. Do outro, professores coagidos a adaptar-se ao que a evolução tecnológica trouxe de novo para a sala de aula e aos diferentes comportamentos que surgiram na comunidade escolar. Presença assídua na escola, o telemóvel surge como um equipamento capaz de fazer emergir as mais variadas representações na sua utilização, sobretudo enquanto recurso educativo. Sendo interdito dentro da sala de aula, por imposição de normativos legais, ele permanece ativo, em silêncio, junto dos alunos e dos professores. O telemóvel tornou-se num acessório de uso quase inevitável pelas gerações mais novas e é utilizado numa diversidade de situações.

Que representações têm os alunos e professores quanto ao uso do telemóvel em contextos educativos? Para tal realizámos um estudo comparativo, transversal, já que a recolha de dados junto do universo foi realizada através de técnicas de registo (questionário), aplicado apenas num dado momento. Seguindo as normas metodológicas, construímos e aplicámos um questionário junto de 179 alunos e 88 professores do $9^{\circ}$ e do $12^{\circ}$ ano de duas escolas de um Agrupamento de uma cidade, capital de um Distrito do Interior. Segundo as opiniões dos inquiridos, os resultados indicam que a sua maioria não se revela muito recetiva à utilização do telemóvel em contextos educativso. Os alunos afirmam não conseguirem indicar uma situação em que os professores pudessem ensinar melhor através do telemóvel, nem tão pouco conseguem imaginar uma situação em que, sozinhos, pudessem aprender melhor com o seu uso. Por outro lado, uma percentagem significativa dos docentes não reconhece vantagens pedagógicas na sua utilização.

\section{Abstract}

The fight against digital illiteracy is one of the greatest challenges facing the school today. On one side are students who have grown up with new technologies. On the other, teachers coerced to adapt to what technological developments brought from November to the classroom and to the different behaviors that arose in the school community. Assiduous presence in the school, the mobile phone emerges as an equipment capable of emerge the most varied representations in its use, mainly as an educational resource. Being banned within the classroom, by imposing legal norms, it remains active, in silence, with students and teachers. The mobile phone has become an almost unavoidable accessory for the younger generations and is used in a variety of situations.

What representations do students and teachers have regarding the use of mobile phones in educational contexts?

For this purpose, we carried out a comparative study, since the collection of data from the universe was performed through registration techniques (questionnaire), applied only at a given moment. Following the methodological norms, we constructed and applied a questionnaire to 179 students and 88 teachers from the 9th and 12th grades of two schools in a grouping of a city, capital of an Interior District. According to respondents' opinions, the results indicate that most of them are not very receptive to the use of mobile phones in educational contexts. Students say they can not point to a situation where teachers can teach better through mobile phones, nor can they imagine a situation where they alone could learn better from their use. On the other hand, a significant percentage of teachers do not recognize pedagogical advantages in their use. 
Palavras Chave: telemóvel e contextos educativos, TIC e educação; m-learning; literacia digital, representações de docentes, representações de alunos, comunicação na escola.

Keywords: mobile phone and educational contexts, ICT and education; m-learning, digital literacy, representations of teachers, student representations; communication in school.

\section{INTRODUÇÃO}

Com a evolução das novas tecnologias, os telemóveis deixaram de ser utilizados apenas para telefonar ou enviar mensagens. Os telemóveis de hoje garantem o acesso à internet e permitem elaborar vídeos, captar fotografias, registar memorandos de voz ou comunicar através de mensagens escritas (SMS). Ou seja, constituem um poderoso meio de comunicação que não deve ser ignorado pela escola.

Todas aquelas características e possibilidades que a utilização do telemóvel fornece poderão ser aproveitadas para o desenvolvimento de atividades educativas na escola. Mas estarão a escola, os professores e alunos prontos para isso?

O uso do telemóvel dentro das salas de aula é proibido na maioria dos estabelecimentos de ensino europeus. Alguns, limitam mesmo a sua utilização dentro do recinto escolar. Em Portugal, cabe a cada estabelecimento de ensino, ou agrupamento de escolas, decidir sobre essa questão, embora o Estatuto do Aluno refira que este não deve "transportar quaisquer materiais, equipamentos tecnológicos, instrumentos ou engenhos, passíveis de objetivamente, perturbarem o normal funcionamento das atividades letivas, ou poderem causar danos físicos ou morais aos alunos ou a terceiros" (Lei 38, 2010: artigo15).

Apesar dessa proibição, muitos alunos continuam a utilizá-los de forma dissimulada, beneficiando das tecnologias inovadoras que lhes estão associadas (Kukulska-Hulme et al, 2009; 2017). Esta nova realidade com que a escola é confrontada faz com que a utilização do telemóvel como recurso educativo nas escolas seja um tema cada vez mais atual junto da comunidade educativa.

\section{A ESCOLA E OS DESAFIOS NA ERA DIGITAL}

Como referimos, a escola debate-se, hoje, com um dos seus maiores desafios: o desafio digital. Os professores, sobretudo estes, mas também toda a comunidade educativa, devem saber encontrar os caminhos certos para tirar partido das novas tecnologias, e das diferentes plataformas de aprendizagem que estão a emergir. Blázquez $(2009 ; 2012 ; 2018)$ refere que com as novas tecnologias de informação e comunicação está a formar-se uma nova sociedade. E a Escola tem que se adaptar aos novos desafios.

Hoje, os jovens que frequentam as nossas escolas são nativos digitais. Isto é nasceram com as novas tecnologias, possuem conhecimentos em determinadas áreas. Conseguem receber e comunicar informação, através de vários meios tecnológicos tradicionais, como a TV ou a rádio, e digitais, como o telemóvel, internet, mail, SMS, redes sociais, de forma síncrona e assíncrona (Ruivo, 2007, 2017).

Preferem claramente o texto "caótico", ou seja, o hipertexto, no qual o leitor escolhe o caminho de leitura em função dos seus interesses, não tendo de obedecer a uma estrutura de um documento definida pelo autor, como acontece, por exemplo, num livro. Para eles, escrever não é apenas escrever com palavras, em suporte papel. Escrever pode ser escrever com palavras, com imagens estáticas ou em movimento. Aderem, por isso, a novas linguagens e, frequentemente, adaptam-se facilmente a novos conceitos de ortografia (ex: SMS, chat).

Este novo tipo de estudante considera que a sua evolução acontece através da partilha de conhecimento e não da aquisição individual do conhecimento. Assim, aprender é um ato mais social que individual. Quanto mais partilha e mais informação partilham com ele, maior é o seu poder, porque mais informação domina. 
Por isso, estes alunos convivem mal com uma escola em que o professor se assume como transmissor de toda a informação, enquanto o aluno se remete à passividade de a receber (Blázquez, 2009; 2012; 2018).

A utilização do telemóvel em contexto educativo não constitui uma novidade em Portugal, embora não sejam muitas as ocasiões em que isso suceda.

O ensino da literatura portuguesa, no Ensino Secundário, constituiu uma experiência desenvolvida por Moura (2008; 2011; 2013; 2014), numa lógica clara de envolver os alunos, de forma intensa, no processo de aprendizagem. "Em vez de procurarmos imagens ou filmes na Internet, fazemos com que os alunos façam parte desse processo, com os seus próprios conteúdos".

A participação dos alunos nesse processo passa também pela apresentação de propostas e o sucesso da utilização do telemóvel enquanto recurso educativo está relacionado com o tipo de representações que alunos e professores têm dessa utilização.

Ferreira (2009) partiu de uma premissa clara: "Gostava que as escolas perdessem o medo de cada vez que um telemóvel está nas mãos de um adolescente". Em vez de ser uma ameaça porque não transformar o aparelho num aliado dos professores?". A investigação decorreu de um estudo de caso com jovens e professores do $3^{\circ}$ ciclo de escolaridade de uma escola de Setúbal, onde foram abordadas as representações e práticas relacionadas com a utilização do telemóvel em contexto escolar. A investigadora explica que tanto os alunos como os professores confirmaram as potencialidades educativas dos telemóveis:

"Os alunos foram capazes de sugerir exemplos significativos de possíveis usos dos telemóveis para atividades escolares, mesmo sem terem tido experiências prévias de utilização deste equipamento digital como recurso educativo. Os professores, embora manifestassem algumas resistências iniciais, tiveram uma atitude global positiva e foram recetivos às propostas feitas pelos alunos". (Ferreira, 2009, p.50).

Em Portugal foram, entretanto, desenvolvidos alguns projetos com vista à utilização do telemóvel como recurso educativo, dos quais destacamos:

- Geração Móvel, da Escola Secundária Carlos Amarante, em Braga (sites.google.com/site/geramovel2/telemóvel) - onde foram definidas diferentes atividades escolares para os alunos desenvolverem com o recurso ao telemóvel, como captar fotografias ou registar datas de testes, por exemplo -;

— SchoolSenses@internet (http://schoolsenses.dei.uc.pt/Default.aspx) - projeto aplicado no $1^{\circ}$ ciclo, e desenvolvido em torno da ideia central da criação de informação multissensorial e georreferenciada, utilizando o telemóvel como um dos seus recursos;

— mLearning (http://nonio.eses.pt/mlearning/conteudos.asp?cod_seccao=1\&cod_sub=1);

- Desenvolvido pela Escola Superior de Educação de Santarém para produção de programas educativos para serem utilizados em telemóveis.

Na Europa, a Comissão Europeia financiou, no âmbito do Programa Leonardo da Vinci, projetos de aprendizagem móvel, com o objetivo de apoiar a educação e formação profissional com o recurso a telefones móveis para a entrega de conteúdos de aprendizagem.

O estudo que realizámos pretendeu dar resposta ao seguinte problema de investigação: quais as representações de professores e de alunos do $3^{\circ}$ ciclo do ensino básico e secundário quanto ao uso do telemóvel em contexto educativo?

Para a sua realização optámos por efetuar um Estudo de Caso transversal, já que a recolha de dados junto do universo a estudar foi realizada através de técnicas de registo (questionário), aplicadas apenas num dado momento.

Deste modo construímos, validámos e aplicámos um questionário junto de alunos e professores dos $9^{\circ}$ e $12^{\circ}$ anos de duas escolas EB3/Secundárias de uma cidade, capital de um Distrito do Interior, o qual procurou dar resposta aos seguintes objetivos de investigação: que diferenças de represen- 
tações têm professores e estudantes sobre a utilização do telemóvel em contexto educativo? Como poderão vir a ser rentabilizados os telemóveis num ambiente escolar? Que recomendações podem daí resultar para a escola, de forma a melhorar os modos de ensinar e o ato de aprender?

\subsection{Caraterização da amostra}

Para a aplicação dos questionários escolhemos duas escolas de uma cidade, capital de um Distrito do Interior, estabelecimentos de ensino que são os únicos que possuem, em simultâneo, turmas de $9^{\circ}$ e $12^{\circ}$ anos. São também duas escolas, do ponto de vista de estratificação social dos alunos, muito semelhantes. As duas escolas estão bem equipadas tecnologicamente.

A escolha intencional destas escolas deve-se ainda ao facto de ambas nos facilitarem totalmente o acesso aos sujeitos para efeitos da aplicação dos questionários.

Neste estudo pretendemos identificar as representações de professores e de alunos dos $9^{\circ}$ e $12^{\circ}$ anos de escolaridade quanto ao uso do telemóvel em contexto educativo.

Para a aplicação do questionário definimos como grupos amostrais a totalidade dos professores do $9^{\circ}$ e $12^{\circ}$ anos, e dos alunos do $9^{\circ}$ ano. Dado que os alunos do $12^{\circ}$ ano constituíam um número muito superior aos do $9^{\circ}$ ano, foi constituída uma amostra de 120 alunos, de um total de 430 sujeitos, de acordo com uma tabela de amostragem (Freixo, 2010).

Assim sendo, os grupos amostrais ficaram constituídos de seguinte forma:

\begin{tabular}{|c|c|c|}
\hline Sujeitos & Professores & Alunos \\
\hline Ano de escolaridade & & 84 \\
\hline $9^{\circ}$ Ano de escolaridade & 20 & 120 \\
\hline $12^{\circ}$ Ano de escolaridade & 77 & 204 \\
\hline Total & 97 & \\
\hline
\end{tabular}

Quadro 1 - Amostra do estudo.

Aplicados os questionários, foi possível recolher 88 questionários de professores, e 179 questionários de alunos, o que constituiu uma taxa de retorno de $90,72 \%$ (docentes) e de $87,74 \%$ (alunos), o que consideramos significativa para a prossecução do estudo.

Verificamos também que a maioria dos indivíduos, quer os professores, quer os alunos, é do sexo feminino, como demonstra o quadro 2 , onde se apresenta o número total de indivíduos que responderam ao questionário. 


\begin{tabular}{|c|c|c|c|c|}
\hline & \multicolumn{2}{|c|}{ Alunos } & \multicolumn{2}{c|}{ Professores } \\
\hline Ano & 9. Ano & $12^{\circ}$ Ano & $9^{\circ}$ Ano & $12^{\circ}$ Ano \\
\hline Sexo & 30 & 42 & 6 & 27 \\
\hline Femenino & 37 & 70 & 19 & 36 \\
\hline Total & 67 & 112 & 25 & 63 \\
\hline $\begin{array}{c}\text { Total } \\
\text { Global }\end{array}$ & & 179 & & \\
\hline
\end{tabular}

Quadro 2 - Número total de indivíduos que responderam ao questionário.

Os sujeitos deste estudo são alunos e professores de duas escolas EB3/Secundárias de uma cidade, capital de um Distrito do Interior. Os estudantes têm idades compreendidas entre os 14 e os 21 anos e frequentam o $9^{\circ}$ e o $12^{\circ}$ ano de escolaridade.

A maioria teve o seu primeiro telemóvel aos 10 anos, mas há quem tenha recebido o seu primeiro aparelho logo aos quatro anos ou apenas aos 16 . Os alunos do $12^{\circ}$ ano possuem telemóveis mais modernos que os do $9^{\circ}$ ano.

Para além do telemóvel estes alunos possuem, na sua maioria $\left(80,59 \%\right.$ no $9^{\circ}$ ano e $85,71 \%$ no $\left.12^{\circ}\right)$ computador portátil. Aparelhos como MP3, PSP e MP4 também são frequentes junto dos alunos dos dois anos de escolaridade. Estamos, por isso, perante uma geração que está perfeitamente ligada às novas tecnologias.

Estes alunos são nativos digitais (Prensky, 2010; 2011) e utilizam com frequência outras formas para comunicar (com a família e com os colegas) e para se informar como a internet, as redes sociais ou Messenger. Por semana, a maioria dos jovens e ambos os anos de escolaridade envia mais de 300 SMS.

Os professores lecionam nas mesmas duas escolas ao $9^{\circ}$ e $12^{\circ}$ anos de escolaridade. Apresentam idades e anos de docência diferentes nos dois níveis de ensino, sendo mais baixa no $9^{\circ}$ ano (a maioria tem entre 26 e 35 anos) e mais elevada no $12^{\circ}$ ano, onde a maioria se situa nos intervalos [36-45 anos] e [46-54 anos]. Isto faz com que cerca de $40 \%$ dos docentes do $9^{\circ}$ ano tenha um tempo de serviço situado entre os 6 e os 15 anos. Em contrapartida no $12^{\circ}$ ano a maioria dos professores tem mais de 36 anos de serviços, embora haja uma percentagem significativa de docentes no intervalo [26-35 anos].

Entre os inquiridos existem docentes de 19 grupos disciplinares diferentes e de 21 disciplinas (a maioria é de ciências/Biologia, Matemática e línguas). $56,8 \%$ do total dos professores exerce cargos nas escolas, sendo que destes a maioria desempenha o cargo de diretor de turma.

A maioria dos docentes tem telemóvel ( $96 \%$ no $9^{\circ}$ ano e $90,5 \%$ no $\left.12^{\circ}\right)$ e uma percentagem significativa $\left(84 \%\right.$ no $9^{\circ}$ ano e $88,9 \%$ no $\left.12^{\circ}\right)$ também possui computador portátil. Verifica-se que não existem diferenças marcantes no tipo de dispositivos que os professores do $9^{\circ}$ ano e do $12^{\circ}$ possuem, estando estes, na sua maioria, capacitados para a captação de imagens e vídeos, acesso à internet, envio de SMS e MMS, ou para ouvir a gravar sons. 


\section{DISCUSSÃO E CONCLUSÕES}

Ao contrário do que sucede com os alunos, os professores, dos dois anos de escolaridade, não enviam muitas mensagens SMS. A maioria não envia mais que 20 mensagens por semana ( $80 \%$ no $9^{\circ}$ ano e $69,8 \%$ no $12^{\circ}$ ano).

Quer os alunos, quer os professores dos dois anos de escolaridade utilizam com frequência o telemóvel dentro da escola, mesmo sabendo que não o podem fazer. A maioria dos alunos do $9^{\circ}$ e $12^{\circ}$ anos têm os telemóveis ligados dentro da sala de aula, sendo que uma grande percentagem os têm ligados, mas no silêncio.

Também a maioria dos docentes dos dois anos de escolaridade tem sempre o telemóvel ligado, mas no silêncio, durante as aulas, isto apesar de reconhecerem que a escola só nos intervalos autoriza a sua utilização. Do mesmo modo, a maioria dos professores não autoriza os alunos a terem o telemóvel ligado nas aulas e aqueles que o permitem, só o fazem em casos excecionais como para receber chamadas urgentes.

Uma percentagem significativa de docentes dos dois anos refere que já tirou o telemóvel a alunos dentro da sala de aula $\left(76 \%\right.$ no $9^{\circ}$ e $50 \%$ no $\left.12^{\circ}\right)$. As principais razões apontadas são, no $9^{\circ}$ ano, utilização indevida do telemóvel, e no $12^{\circ}$ ano o facto de ser contra o regulamento.

Dentro da sala de aula, os alunos do $9^{\circ}$ e $12^{\circ}$ anos de escolaridade utilizam o telemóvel, sobretudo, para enviar e receber SMS (no $9^{\circ}$ ano todos os alunos disseram ter recebido, enquanto que no envio os alunos do $12^{\circ}$ ano levam vantagem). Ou seja, continuam a utilizá-lo de forma dissimulada, beneficiando das tecnologias que lhes estão associadas (Kukulska-Hulme et al 2009; 2017).

Fora da sala, as mensagens também são o meio escolhido para os jovens tirarem dúvidas com os colegas. Mas quando é necessário estudar, os alunos dos dois anos de escolaridade preferem claramente o livro da disciplina e o caderno da aula. O recurso ao Youtube e à Wikipédia também é frequente, mas com percentagens mais baixas.

No que respeita à utilização do telemóvel para copiar nos testes, os resultados não deixam de ser curiosos. A maioria dos alunos do $9^{\circ}$ e $12^{\circ}$ anos afirmam nunca ter copiado nos testes através do telemóvel. Mas uma maioria ainda mais significativa $\left(81,5 \%\right.$ no $9^{\circ}$ ano e $90,1 \%$ no $\left.12^{\circ}\right)$ refere conhecer colegas que o fizeram.

De igual modo, quando confrontados com o facto de terem sido vítimas de bullying, através do telemóvel, a maioria responde negativamente, mas quando perguntamos se conhecem colegas que tenham sofrido esse tipo de pressão, cerca de metade dos inquiridos dos dois anos de escolaridade responde positivamente quer pelo envio de imagens, quer de SMS. Os próprios docentes do $9^{\circ}$ ano (56\%) confirmam a existência de bullying junto dos seus alunos.

Aqueles dados vêm ao encontro dos resultados do Euro barómetro 248 (2008). Um estudo desenvolvido na Europa, o qual revela uma elevada preocupação dos pais, sobre o facto dos seus filhos poderem vir a sofrer bullying pela internet, ou pelo telemóvel.

Verifica-se ainda que a maioria dos alunos dos alunos do $9^{\circ}$ ano $(65,2 \%)$ diz que a utilização do telemóvel dentro da sala de aula deveria ser permitida, enquanto que, em sentido contrário, $67 \%$ dos alunos do $12^{\circ}$ ano diz que essa utilização não deveria ser possível.

Estes dados confirmam também os resultados do estudo E-Generation (2007), onde se refere que "o telemóvel se tornou num acessório - para as novas gerações - quase obrigatório e é transportado para uma série de situações diária, desde as aulas, aos tempos lúdicos e aos tempos passados com a família e ou com os amigos" (:167).

Mas de que forma utilização do telemóvel enquanto recurso educativo é aceite pelos jovens?

A maioria dos alunos do $9^{\circ}$ e $12^{\circ}$ anos não consegue apresentar alguma situação em que os professores os pudessem ensinar melhor um assunto através do telemóvel.

O mesmo sucede quando confrontados com a questão de saber se conseguiam apresentar uma situação em que pudessem aprender melhor um assunto através do telemóvel. 
Ainda assim, na perspetiva dos alunos inquiridos, a utilização do telemóvel em contexto educativo pode ser feita de várias formas: como calculadora, para escrever pequenos textos, para a elaboração de pequenos filmes ou vídeos, em visitas de estudo fora da escola, para aceder à internet, para funcionar como agenda ou para captar fotografias que venham a ilustrar trabalhos escolares.

O uso do telemóvel como auxiliar de memória durante os testes, revela-nos diferenças importantes entre os dois anos de escolaridade: os alunos do $12^{\circ}$ mostram-se pouco recetivos e os de $9^{\circ}$ mais acolhedores. Uma tendência seguida no uso do telemóvel como auxiliar de memória na realização de trabalhos. No que respeita ao uso do telemóvel para gravação de aulas, verifica-se que os alunos do $9^{\circ}$ ano estão mais recetivos a fazê-lo, que os do $12^{\circ}$ ano.

E os professores, utilizam o telemóvel em questões de trabalho? Conseguem apresentar alguma situação em que o telemóvel possa funcionar como recurso educativo? Afinal quais são as suas representações?

A maioria dos professores do $9^{\circ}$ ano e do $12^{\circ}$ ano inquiridos diz telefonar aos colegas e aos amigos sobre questões da escola. Esses telefonemas tanto acontecem através do telemóvel, como pelo telefone fixo. O recurso aos SMS quer para contactar colegas e amigos sobre assuntos relacionados, ou não, com a escola, também é muito utilizado pelos professores. O mesmo sucede no envio de SMS a familiares.

$68 \%$ dos professores do $9^{\circ}$ ano e $69,8 \%$ dos docentes do $12^{\circ}$ ano não vê vantagens pedagógicas na utilização do telemóvel. Além disso, a maioria dos docentes inquiridos revela que o uso do telemóvel "pode constituir uma fonte de distúrbios na escola"

Os docentes que reconheceram vantagens pedagógicas na utilização do telemóvel, dão como justificação o facto de "não se importarem de experimentar o telemóvel enquanto recurso educativo, de o utilizarem como calculadora, para melhorar as competências linguísticas, para a produção de pequenos filmes/vídeos, captar fotografias, em visitas de estudo, para aceder à internet ou como agenda para trabalhos e testes".

Os que não reconhecem vantagens pedagógicas asseguram que a sua utilização é um fator de distração. Além disso, uma elevada percentagem de docentes não vê nenhuma vantagem na utilização do telemóvel na sala de aula, nem tão pouco consegue imaginar uma situação em que a utilização do telemóvel traga vantagens. Por isso, afirmam na sua maioria que o telemóvel é útil fora da sala de aula, mas não lá dentro.

O estudo revela-nos que são evidentes as representações que os alunos e os professores dos dois anos de escolaridade têm sobre o uso do telemóvel em contexto educativo.

Ferreira (2009) partiu de uma premissa clara: "Gostava que as escolas perdessem o medo de cada vez que um telemóvel está nas mãos de um adolescente". Em vez de ser uma ameaça porque não transformar o aparelho num aliado dos professores?". O nosso estudo revela-nos que os professores não veem o telemóvel como um aliado no contexto educativo. Diz-nos também que os alunos estão mais empenhados em enviar SMS, a partir da sala de aula, do que a utilizar o telemóvel para questões educativas.

Também os nossos objetivos de investigação foram alcançados. Pretendemos apurar "como poderão vir a ser rentabilizados os telemóveis num ambiente escolar".

Concluímos que as representações de professores e alunos do $3^{\circ}$ ciclo do ensino básico e do secundário quanto ao uso do telemóvel em contexto educativo são convergentes no principal ponto de análise da nossa investigação: a utilização do telemóvel em contexto educativo - representações de alunos e professores dos $9^{\circ}$ e $12^{\circ}$ anos.

A maioria dos alunos diz não conseguir apresentar uma situação em que os professores os pudessem ensinar melhor um assunto através do telemóvel, nem tão pouco conseguem imaginar uma situação em que pudessem aprender melhor um assunto através do telemóvel. Por outro lado, uma percentagem significativa dos docentes não reconhece vantagens pedagógicas na sua utilização.

Tratando-se de um estudo de caso, os resultados não são passíveis de serem generalizados. No entanto, pensamos que este estudo apresenta, ainda assim, indicadores válidos e relevantes para uma reflexão sobre o uso das tecnologias nas escolas e em particular sobre aquelas que remetem para a mobilidade. 


\section{REFERÊNCIAS BIBLIOGRÁFICAS}

Afonso, N. (2005). Investigação Naturalista em Educação. Um guia prático e crítico. Porto: Edições ASA.

Blázquez, F. (2009). O professor do século XXI. Comunicação oral (Oração de sapiência), proferida em novembro de 2009, no Instituto Politécnico de Beja.

Blázquez, F., Tosina, R., Díaz, L., (2012). La e-evaluación de aprendizajes en educación superior a través de aulas virtuales síncronas. Revista científica iberoamericana de comunicación y educación, 39, 159-167.

Blázquez, F. (2018). Aprender y enseñar en la era digital. Ensino Magazine, 242, p.19. Castelo Branco: RVJ Editores.

Decreto de Lei 39/2010. Estatuto do Aluno. Diário da República, 1. ${ }^{a}$ série - N. ${ }^{\circ} 171-2$ de setembro (2010). http://www. idesporto.pt/ficheiros/file/Lei_39_2010.pdf.

Ferreira, E. (2009). Telemóvel na sala de aula. Para usar sem limites. http://www.ionline.pt/conteudo/4439-telemovel-na-sala-aula-usar-sem-limites-diz- professora.

Ferreira, E. (2009). Jovens, Telemóveis e Escola. Projeto de Mestrado em Gestão de Sistemas de e-Learning. Braga: Universidade do Minho.

Freixo, M. (2010). Metodologia Científica - Fundamentos Métodos e Técnicas (2ª Edição). Lisboa: Edições Piaget.

Geração Móvel (2011). http://sites.google.com/site/geramovel2/telemovel.

Kukulska-Hulme, A., Sharples, M., Milrad, M., Arnedillo-Sánchez, I. \& Vavoula, G. (2009) Innovation in Mobile Learning: a European Perspective. International Journal of Mobile and Blended Learning, 1 (1), pp. 13-35.

Kukulska-Hulme, A., Ferguson, R., Barzilai, S., Ben-Zvi, D., Chinn, C.A., Herodotou, C., Hod, Y., Kali, Y., Kupermintz, H., McAndrew, P., Rienties, B., Sagy, O., Scanlon, E., Sharples, M., Weller, M., \& Whitelock, D. (2017). Innovating Pedagogy 2017: Open University Innovation Report 6. 12.

Moura, A. (2009). O Telemóvel para ouvir e gravar Podcasts: exemplos no Ensino Secundário. Encontro sobre Podcasts. Braga: Universidade do Minho.

Moura, A. (2008). M-Learning, quando o telemóvel ensina a estudar. WebAula. Braga: Universidade do Minho.

Moura, A.(2011). Apropriação do telemóvel como ferramenta de mediação em mobile learning:estudos de caso em contexto educativo. (Tese de Doutoramento). Instituto de Educação da Universidade do Minho. http://hdl.handle. net/1822/13183.

Moura, A., Carvalho A (2013). Framework for mobile learning integration into educational contexts. Journal Handbook of mobile learning, 4. 58-69.

Moura, A., Carvalho A., Cruz S., Marques C., Santos I. (2014). Os jogos mais jogados pelos alunos do Ensino Básico ao Ensino Superior. Atas do $2 .^{\circ}$ Encontro sobre Jogos e Mobile Learning. Braga: CIEd. Universidade do Minho.

Prensky, M. (2010). Teaching Digital Natives: Partnering for Real Learning. New York: Sage Publications Inc.

Prensky, M. (2004).What_Can_You_Learn_From_a_Cell_Phone? www.marcprensky.com/writing/Prensky-What_Can_You_ Learn_From_a_Cell_Phone- FINAL.pdf.

Prensky, M. (2011). A emergente vida on-line dos Nativos Digitais. Brasil: Phorte Editora.

Prensky, M. (2010). Teaching Digital Natives: Partnering for Real Learning. New York: Sage Publications Inc.

Ruivo, J. (2007). Educação \& Desenvolvimento. Castelo Branco: RVJ - Editores.

Ruivo, J. (2017). Escola: Uma Tribo Global. Castelo Branco: RVJ - Editores.

SchoolSenses@internet. (2011). http://schoolsenses.dei.uc.pt/Default.aspx. 